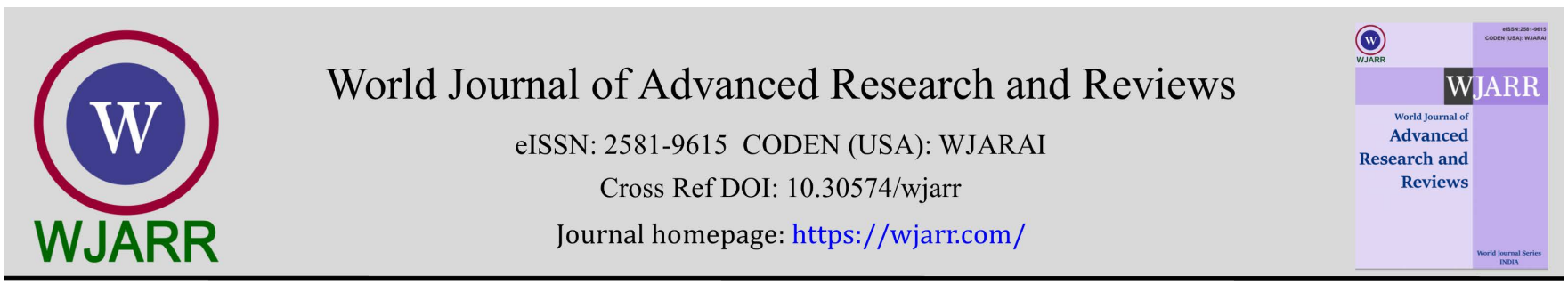

(RESEARCh ARTICLE)

Check for updates

\title{
The pattern of central corneal thickness in patients attending a Tertiary Hospital in Dar-Es-Salaam
}

Annamary Stanislaus 1, *, Ntsilane Susan Mosenene 1, Celina Mhina 1, John Stanslaus Kisimbi 1, Frederick Robert Burgess ${ }^{2}$, Milka Madaha Mafwiri ${ }^{1}$, Dilawar Padhan ${ }^{1}$ and Anna John Sanyiwa ${ }^{1}$

${ }^{1}$ Department of Ophthalmology, Muhimbili University of Health \& Allied Sciences. Box 65001, Dar es Salaam Tanzania.

2 School of Medicine, University of St Andrews, UK

World Journal of Advanced Research and Reviews, 2021, 09(02), 127-133

Publication history: Received on 14 January 2021; revised on 15 February 2021; accepted on 17 February 2021

Article DOI: https://doi.org/10.30574/wjarr.2021.9.2.0056

\begin{abstract}
Background: Central Corneal Thickness (CCT) is an indicator of corneal health status as well as being an essential tool in assessment and management of corneal diseases. It is an important factor in the diagnosis and management of glaucoma as it affects the measurement of intraocular pressure. However, the pattern of central corneal thickness in our population is not known. Our study aimed to describe the CCT measurements and their variation with age and sex among patients attending the eye clinic at Muhimbili National Hospital (MNH), in Dar es Salaam, Tanzania.
\end{abstract}

Methodology: A hospital-based descriptive, cross-sectional study used convenient sampling to recruit adult patients aged 18 years and above, presenting to the MNH between August 2016 and January 2017.Visual acuity assessment, Goldman applanation tonometry and CCT assessment using an ultrasound pachymeter were performed. Patients with previous intraocular surgery were excluded.

Results: A total of 398 patients (208 males and 190 females) were recruited. The mean CCT was $526.64 \pm 38.30 \mu$ m; being $523.99 \pm 38.20 \mu \mathrm{m}$ for males and $529.7 \pm 38.3 \mu \mathrm{m}$ for females. $226(56.85 \%)$ had CCT of less than $520 \mu \mathrm{m}$.There was no statistically significant difference in CCT between gender. The proportion of patients with thinner CCT increased with increasing age from $25.8 \%$ in those $<30$ years to $75 \%$ in those aged 71 years and above. The mean CCT decreased with increasing age with $\mathrm{P}$-value $<0.001$.

Conclusion: The average CCT in patients attending Muhimbili National Hospital is $526.64 \mu \mathrm{m}$ (SD 38.30) which is generally thin, inversely proportion to age and similar that of other Africans and African-Americans. This finding has implications for the management of glaucoma in this population.

Keywords: Central Corneal Thickness; age; Africans

\section{Introduction}

Central Corneal Thickness (CCT) is a measure of the thickness of the cornea at the center. The thickness of the cornea is largely determined by the degree of hydration. The human cornea is thinner at the center and gets progressively thicker towards the periphery. Normally, the peripheral corneal thickness range from 0.68 to $0.89 \mathrm{~mm}$, while CCT ranges from 0.52 to $0.61 \mathrm{~mm}[1,2]$. The average CCT is $540 \mu \mathrm{m}$ although this varies between individuals according to age group, gender and ethnicity.

\footnotetext{
* Corresponding author: Annamary Stanislaus

Department of Ophthalmology, Muhimbili University of Health \& Allied Sciences. Box 65001, Dar es Salaam Tanzania.

Copyright $(2021$ Author(s) retain the copyright of this article. This article is published under the terms of the Creative Commons Attribution Liscense 4.0.
} 
The effect of gender on CCT is controversial with some studies showing no significant correlation between gender and CCT[3] while others show a modest effect of gender on CCT. Some studies report slightly thicker corneas in men[4] whilst other studies have shown thicker CCT among females than males[5]. People of African origin have been noted to have thinner CCT compared to Caucasians[6].

Central corneal thickness is an important indicator of corneal health status as well as being an essential tool in assessment and management of corneal diseases as it gives an estimate of the corneal barrier and endothelial pump function[7]. Additionally, CCT is important when determining a patient's eligibility and choosing the modality of laser refractive surgery[8].

Central corneal thickness (CCT) has recently emerged as an important factor in the diagnosis and management of glaucoma as it has been established that it affects the measurement of intraocular pressure (IOP)[9]. Thicker corneas resist the indentation inherent in nearly all methods of IOP measurements. Conversely, thinner corneas undergo higher indentation during assessment, giving falsely low IOP [10] Further research has shown that CCT is reduced in patients with the diagnosis of "low tension glaucoma," suggesting that, in at least some of these individuals, IOP is being underestimated because of thin corneas[11].

As a key element in the management of glaucoma, IOP should be measured using a reliable technique with a high degree of accuracy. Though Goldman applanation tonometry (GAT) is the most widely used and current "gold standard" for IOP measurement, readings of IOP made with GAT are affected by CCT[11]. IOP correction values for various CCT measures[12] are routinely used.

Despite having many patients with open angle glaucoma, including the low-tension type, at Hospital MNH eye clinic, CCT is not assessed to help in the diagnosis and management of these patients. Moreover, there are no studies reported on the pattern of CCT in this population. Knowing the pattern of CCT in our setting will help to identify patients who are more likely to develop glaucoma, and to properly manage patients with low tension glaucoma who might seem to have falsely low IOP due to their thin corneas. The aims of the study were to specifically describe the CCT measurements and to determine the variation of CCT with age and sex among patients attending the eye clinic at MNH.

\section{Methodology}

\subsection{Study setting and design}

This was a descriptive, hospital-based cross-sectional study which was conducted at MNH, Dar es Salaam, Tanzania. The hospital serves patients from Dar-es-Salaam and other regions across the country. Data was collected from the adult eye clinic which attends an average of 70 adult patients (aged 18 years and above) daily from Monday to Friday. The estimated sample size to give precision of 0.05 at $95 \%$ CI was 384 patients.

\subsection{Study population}

All patients attending the adult eye clinic during the study period were eligible for the study.

Inclusion criteria: Convenience sampling was used to recruit all adult patients aged 18 years and above who were attending the adult eye clinic at MNH on Mondays and Wednesdays during the study period, August 2016 to January 2017.

Exclusion criteria: Patients with any corneal pathology and those who had undergone intraocular surgery were excluded as intraocular surgery affects endothelial cell count and may reduce CCT.

\subsection{Data collection procedures}

Eligible patients were informed about the study. Patients who consented were recruited and ocular assessment commenced. Visual acuity was taken using Snellen's charts for literate and illiterate patients. A Topcon slit lamp biomicroscope was used for examination of the anterior segment of the eye to detect any corneal pathology. The IOP of each eye was measured using the Goldman applanation tonometer. The tonometer was calibrated prior to the commencement of the study to ensure quality results. Central Corneal Thickness was measured using an ultrasound pachymeter (model 55B; DGH Technology, Inc.). A drop of topical anaesthesia was applied to the eye then a sterile pachymeter tip gently touched the cornea. Five readings were taken and the mean was recorded as the CCT of that particular patient. CCT was classified as: thin $(<520 \mu \mathrm{m})$, normal $(520-560 \mu \mathrm{m})$ and thick $(>560 \mu \mathrm{m})$. All information was recorded on a questionnaire. 


\subsection{Data analysis}

Data were analysed using the Statistical Package for Social Sciences (SPSS 20.0, Chicago, IL). Means were used for continuous data while categorical data are presented as percentages. Correlation between age, sex and CCT were ascertained using chi squared test where a two-sided p-value of less than 0.05 was considered statistically significant.

\subsection{Ethical considerations}

The Research and Publications Committee of MUHAS granted ethical approval for the study. Permission to conduct the study at MNH was given by the Chief Executive Director. All patients consented before inclusion in the study. Confidentiality was maintained throughout data collection and management.

\section{Results}

A total of 398 patients were recruited and were all included in the analysis. The age range was 18-95 years. The study population mean age was 53.92(SD 18.44), while the mean age for males and females was 52.75(SD 16.25), and 54.10 (SD 18.52) respectively. The majority (48.7\%) of patients were aged between 51 and 70 years. There were slightly more males $(52.3 \%)$ than females (Table 1$)$.

Table 1 The socio-demographic characteristics of the study population $(\mathrm{N}=398)$.

\begin{tabular}{|l|l|l|}
\hline Character & Frequency (n) & Percentage (\%) \\
\hline Age category (Years) & & \\
\hline Less than 30 & 62 & 15.6 \\
\hline 31 to 50 & 82 & 20.6 \\
\hline 51 to 70 & 194 & 48.7 \\
\hline 71 and above & 60 & 15.1 \\
\hline Sex & & \\
\hline Male & 208 & 52.3 \\
\hline Female & 190 & 47.7 \\
\hline
\end{tabular}

More than half (56.8\%) of patients had CCT of less than $520 \mu \mathrm{m}$, and only $9 \%$ had CCT of more than $560 \mu \mathrm{m}$ (Figure 1. .).

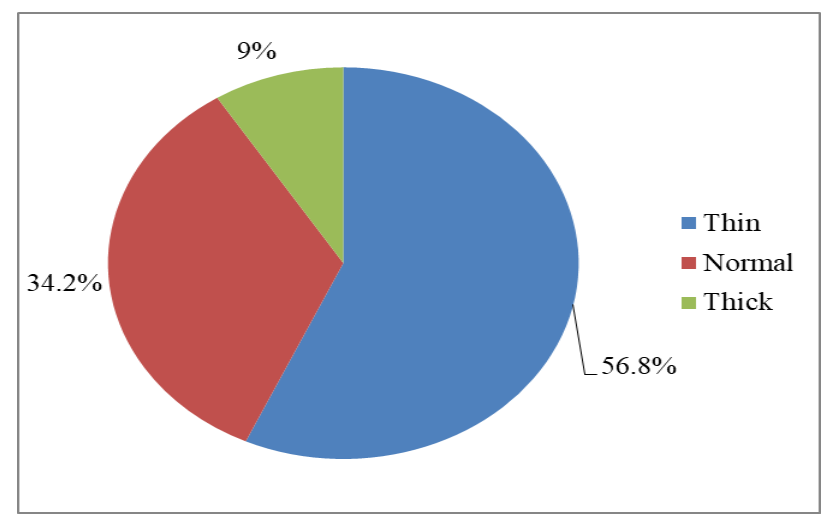

Figure 1 Central Corneal Thickness measurements among patients attending ophthalmology clinic at Muhimbili National Hospital. 
Table 2 Mean CCT of the study population.

\begin{tabular}{|l|l|l|l|l|}
\hline Variable & Thin & Normal & Thick & \multirow{2}{*}{ Overall $(\boldsymbol{\mu m})$} \\
\hline & $<520 \mu \mathrm{m}$, & $520-560 \mu \mathrm{m}$ & $>560 \mu \mathrm{m}$. & \\
\hline Mean CCT $(\mu \mathrm{m})$ & & & & \\
\hline Mean $(\mathrm{SD})(\mu \mathrm{m})$ & $499.03(36.4)$ & $532.01(6.4)$ & $554.11(41.7)$ & $526.64(38.30)$ \\
\hline Minimum CCT & 428.00 & 520.00 & 560.00 & 428.00 \\
\hline Maximum CCT & 519.00 & 559.00 & 625.00 & 625.00 \\
\hline
\end{tabular}

The overall mean CCT was $526.64 \pm 38.30 \mu \mathrm{m}$ (range $428 \mu \mathrm{m}-625 \mu \mathrm{m}$ ).

Table 3 Variation of Central Corneal Thickness with Age

\begin{tabular}{|c|c|c|c|c|c|}
\hline Character & \multicolumn{3}{|c|}{ CCT } & \multirow[t]{2}{*}{ TOTAL } & \multirow[t]{2}{*}{ Mean $(S D)(\mu \mathrm{m})$} \\
\hline Age (years) & $\begin{array}{l}\text { Thin } \\
<520 \mu \mathrm{m} \text {, }\end{array}$ & $\begin{array}{l}\text { Normal } \\
520-560 \mu \mathrm{m} \text {, }\end{array}$ & $\begin{array}{l}\text { Thick } \\
>560 \mu \mathrm{m} \text {, }\end{array}$ & & \\
\hline & (No, \%) & $(\mathrm{No}, \%)$ & (No, \%) & & \\
\hline$<30$ & $16(25.8)$ & 23 (37.1) & $23(37.1)$ & $62(100)$ & $546.8(43.6)$ \\
\hline 31 to 50 & $30(36.6)$ & 44 (53.7) & $8(9.8)$ & $82(100)$ & $528.1(37.6)$ \\
\hline 51 to 70 & $135(69.6)$ & $54(27.8)$ & $5(2.6)$ & $194(100)$ & $523.7(33.9)$ \\
\hline 71 and above & $45(75)$ & $15(25)$ & $0(0)$ & $60(100)$ & $513.4(39.6)$ \\
\hline $\begin{array}{l}\text { Total } \\
\text { p-value }\end{array}$ & $\begin{array}{l}226(56.8) \\
<0.001\end{array}$ & $\begin{array}{l}136(34.2) \\
0.002\end{array}$ & $\begin{array}{l}36(9) \\
<0.001\end{array}$ & 398 & $<0.001$ \\
\hline
\end{tabular}

The proportion of patients with thin CCT increased with increasing age group from $25.8 \%$ in those $<30$ years to $75 \%$ in those aged 71 years and above. The mean CCT decreased with increasing age from $546.8 \mu \mathrm{m}$ in those of less than 30 years to $513.4 \mu \mathrm{m}$ in those aged 71 years and above. This variation was statistically significance with $p$-value $<0.001$.

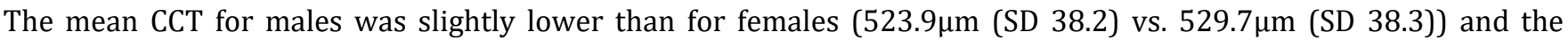
proportion of male patients with thin CCT was slightly higher than females (61.1\% vs. 52.1\%), but this was not statistically significant $(\mathrm{p}=0.065)$. The proportion of females with normal and thick CCT was $35.3 \%$ and $12.6 \%$ respectively. The proportion of males with normal and thick CCT was $33.2 \%$ and $5.8 \%$ respectively, although there was no statistical significance in these differences between genders.

In univariate analysis, different factors were found have a statistically significant association with thin CCT. Compared to patients aged less than 30 years, those aged 50 years and above were 6 times more likely to have thin CCT while the odds of having thin CCT among those aged more than 70 years was 8 times higher. The odds of having a thin CCT for patients with a history of glaucoma was 1.5 while it was twice for intra ocular pressure of 21-25mmHgcompared to IOP of less than $15 \mathrm{mmHg}$ (Table 4).

In multivariate analysis age was the only factor which was found to have statistically significant association with thin CCT (OR 4.4, 95\% CI 2.4-8.2, p<0.001). Neither having primary open angle glaucoma (OR 1.3, 95\% CI 0.9-2.0, p=0.203) nor higher IOP (OR 1.2, 95\% CI 0.8-2.0, p=0.402) was statistically significantly associated with thin CCT. 
Table 4 Univariate analysis on thin CCT.

\begin{tabular}{|c|c|c|c|c|}
\hline \multirow[t]{2}{*}{ Variable } & \multirow[t]{2}{*}{ Odds Ratio } & \multicolumn{2}{|c|}{ 95\% Confidence Interval } & \multirow[t]{2}{*}{ p-value } \\
\hline & & Lower & Upper & \\
\hline \multicolumn{5}{|c|}{ Age category (Years) } \\
\hline Less than 30 & 1.000 & & & \\
\hline 31 to 50 & 1.659 & 0.803 & 3.424 & 0.171 \\
\hline 51 to 70 & 6.578 & 3.448 & 12.55 & $<0.001$ \\
\hline 71 and above & 8.625 & 3.816 & 19.50 & $<0.001$ \\
\hline \multicolumn{5}{|l|}{ Sex } \\
\hline Male & 1.000 & & & \\
\hline Female & 0.694 & 0.466 & 1.033 & 0.072 \\
\hline \multicolumn{5}{|c|}{ History of POAG } \\
\hline No & 1.000 & & & \\
\hline Yes & 1.643 & 1.084 & 2.941 & 0.019 \\
\hline \multicolumn{5}{|c|}{ Intra-ocular pressure (mmHg) } \\
\hline$<15$ & 1.000 & & & \\
\hline $15-20$ & 0.969 & 0.597 & 1.571 & 0.898 \\
\hline $21-25$ & 2.442 & 1.336 & 4.467 & 0.004 \\
\hline $26-30$ & 1.050 & 0.302 & 3.655 & 0.939 \\
\hline$>30$ & 0.350 & 0.103 & 1.187 & 0.092 \\
\hline
\end{tabular}

\section{Discussion}

To our knowledge, this was the first study conducted on the pattern of CCT in Tanzania. Understanding the pattern of CCT of any given population is important in order to predict the risk of glaucoma in that population. Racial variation has been reported to have influence on CCT[13]. This implies that the mean CCT in different populations will be different. In this study the mean central corneal thickness was $526.64(38.30) \mu \mathrm{m}$. This result is similar to that of previous studies among Africans and African-Americans in USA[13] and Cameroon[14]. However the mean CCT of our study population was thinner than those among Caucasians[15].

Our results show that more than half $(56.8 \%)$ of the study population had thin corneas (with CCT of less than $520 \mu \mathrm{m}$ ) while only $9 \%$ had thick corneas (with CCT of more than $560 \mu \mathrm{m}$ ). These findings are in agreement with the previous findings that Africans and African-Americans have thinner CCTs[6]. In a study comparing Caucasians and AfroAmericans LaRosa et al showed that African-Americans had thinner CCT measurements than Caucasians[13] The reason for the thinner corneas among the black population is not clearly known but genetic factors have been proposed as one of the causes [16]. In the current study, CCT was observed from 428 to $625 \mu \mathrm{m}$ which supports the hypothesis of the existence of structural variations among different people even of the same ethnic and racial group[1].

The age range in this study was 18 years to 95 years with a mean age of 53.92 (SD 18.44) years. This study demonstrated a significant decrease in CCT with increasing age whereby elderly patients were found to have thinner CCT as compared to younger patients. Furthermore, in this study, a higher proportion (81.7\%) of patients aged 71 years and above had CCT of less than $520 \mu \mathrm{m}$ and this age group also had the lowest mean CCT. This was in contrast to younger patients of less than 30 years in whom only about $1 / 3(36.6 \%)$ of patients had thin CCT and their mean CCT was comparatively higher (513.4(SD 39.6) $\mu \mathrm{m}$ vs. 546.8 (SD 43.6) $\mu \mathrm{m}$ ). This was similar to previous studies done in Ethiopia [17] and America[6] that demonstrated that age affects CCT. In univariate analysis, being older than 50 years increased 
the risk of having a thin cornea by 6 -fold while at $70+$ years, the risk was 8 times higher. In multivariate analysis age was the only factor that was found to affect CCT and this was statistically significant.

Reduction of CCT in older people can be explained by the reduction in the density of keratocytes, the major cellular component of the cornea stroma, and by the possible destruction of collagen fibers as part of the normal aging process. Additionally, old people are exposed to environmental factors for longer periods which can influence the structure of the cornea and hence reduce CCT[18].

Results of this study showed no statistically significant difference in mean CCT between males and females, similar to previous studies[3] Majority of studies that analyzed the effect of sex on CCT were done among young populations; one of the reasons for this variation has been reported to be due to hormonal differences[7]. The population in the current study were adults aged 18 years and above with more than half (63.8\%) of them being more than 50 years. This age group has different hormonal characteristics compared to younger people[3].

This study was a hospital based study where all patients attended for various eye conditions likely to cause selection bias. This was minimized by excluding eye conditions with a potential to affect CCT.

\section{Conclusion}

The mean CCT value in this study is 526.64(SD 38.30) $\mu \mathrm{m}$. This is generally thin but closely matches with that of other Africans and African-Americans. The CCT was inversely proportion to age. There was no significant variation between CCT and sex. This finding is important in identification and management of patients with glaucoma and thin corneas. Measurements of the IOP for such patients need to be corrected for corneal thickness. This will only be possible if pachymeters for measuring CCT are available in ophthalmology clinics to facilitate CCT measurements and consequently accurate IOP measurements, and therefore the appropriate management of glaucoma.

\section{Compliance with ethical standards}

\section{Acknowledgments}

Thanks to all the staff of the department of Ophthalmology of Muhimbili National Hospital who helped in the preparation of this work and the Ministry of Health Social Welfare, Gender, Elderly and Children in Tanzania for sponsoring the study.

\section{Disclosure of conflict of interest}

The authors have no proprietary interest in any materials mentioned in this article.

\section{Statement of ethical clearance}

The Research and Publications Committee of MUHAS granted ethical approval for the study. Permission to conduct the study at MNH was given by the Chief Executive Director. All patients consented before inclusion in the study. Confidentiality was maintained throughout data collection and management.

\section{Statement of informed consent}

Informed consent was obtained from all individual participants included in the study.

\section{Authors' contributions}

AS: designed the study, collected data, performed data analysis, and wrote the report and prepared the manuscript. SM, CM, JSK, MMM, DH, and AJS: participated in the study design, data collection, report writing and manuscript preparation. FB: Participated in preparation of the manuscript.

\section{References}

[1] Iyamu E, Iyamu JE, Amadasun G. Central corneal thickness and axial length in an adult Nigerian population. J Optom. 2013; 6(3): 154-60. 
[2] Gromacki SJ, Barr JT. Central and peripheral corneal thickness in keratoconus and normal patient groups. Optom Vis Sci. 1994; 71(7): 437-41.

[3] Iyamu E, Osuobeni E. Age, gender, corneal diameter, corneal curvature and central corneal thickness in Nigerians with normal intra ocular pressure. J Optom. 2012; 5(2): 87-97.

[4] Sakalar YB, Keklikci U, Unlu K, Alakus MF, Yildirim M, Dag U. Distribution of central corneal thickness and intraocular pressure in a large population of Turkish school children. Ophthalmic Epidemiol 2012; 19(2): 83-8.

[5] Brandt JD, Beiser JA, Kass MA, Gordon MO. Central corneal thickness in the Ocular Hypertension Treatment Study (OHTS). Ophthalmology. 2001.

[6] Brandt JD, Gordon MO, Beiser JA, Lin SC, Alexander MY, Kass MA, et al. Changes in Central Corneal Thickness The Ocular Hypertension Treatment Study. 2008; 1550-7.

[7] Dai E, Gunderson CA. Pediatric central corneal thickness variation among major ethnic populations. J AAPOS 2006; 10(1): 22-5.

[8] Rashmi S, Soman S, Anupama B, Hegde V. Do Postmenopausal Women have Thinner Central Corneal Thickness as Compared to Women in Reproductive Age Group: IJSR. 2016; 5(3): 2188-91.

[9] Wei W, Fan Z, Wang L, Li Z, Jiao W, et al. Correlation Analysis between Central Corneal Thickness and Intraocular Pressure in Juveniles in Northern China: The Jinan City Eye Study. PLoS ONE. 2014; 9(8): 1-7.

[10] Toh T, Liew SHM, MacKinnon JR, Hewitt AW, Poulsen JL, Spector TD, et al. Central corneal thickness is highly heritable: The twin eye studies. Investig Ophthalmol Vis Sci. 2005; 46(10): 3718-22.

[11] Ehlers N, Bramsen T, Sperling S. Applanation tonometry and central corneal thickness. Acta Ophthalmol. 1975; 53(1): 34-43.

[12] Copt RP, Thomas R, Mermoud A. Corneal thickness in ocular hypertension, primary open-angle glaucoma, and normal tension glaucoma. Arch Ophthalmol. 1999; 117(1): 14-6.

[13] La Rosa FA, Gross RL, Orengo-Nania S. Central corneal thickness of Caucasians and African Americans in glaucomatous and nonglaucomatous populations. Arch Ophthalmol. 2001; 119(1):

[14] Andrew OE. Central corneal thickness and intraocular pressure in the Cameroonian nonglaucomatous population. Clin Ophthalmol. 2010; 717-24.

[15] Gros-Otero J, Arruabarrena-Sánchez C, Teus M. Central corneal thickness in a healthy Spanish population. Arch Soc Esp Oftalmol. 2011; 86(3): 73-6.

[16] Zheng Y, Huang G, Huang W, He M. Distribution of central and peripheral corneal thickness in Chinese children and adults: the Guangzhou twin eye study. Cornea. 2008; 27(7): 776-81.

[17] Gelaw Y. The impact of central corneal thickness on intraocular pressure among Ethiopian glaucoma patients: a cross-sectional study. BMC Ophthalmology. 2012; 12(1): 1.

[18] Alsbirk PH. Corneal thickness. II. Environmental and genetic factors. Acta Ophthalmol. 1978; 56: 105-13. 